\title{
Association between PSA and age in Macuxi ethnic population of the Brazilian Amazon forest region
}

This article was published in the following Dove Press journal:

Research and Reports in Urology

\author{
Mário Maciel de Lima \\ Junior ${ }^{\prime}$ \\ Sebastião Salazar Jansem \\ Filho $^{2}$ \\ Marcos Tobias-Machado 3 \\ 'Department of Urology, State \\ University of Roraima, Boa Vista, \\ Brazil; '2Department of Urology, \\ Cathedral College, Boa Vista, Brazil; \\ ${ }^{3}$ Section of Urologic Oncology, \\ Department of Urology, ABC Medical \\ School, Sao Paulo, Brazil
}

Purpose: Prostate cancer is one of the most common cancers in men, with higher prevalence in developed countries. Nothing much is known regarding the incidence and mortality of prostate cancer in Brazilian population or among the indigenous groups in Brazil. Therefore, this study aimed to correlate prostate-specific antigen (PSA) level and age in the tribe with Macuxi ethnicity, from the jungles of Amazon (between Brazil and Venezuela).

Patients and methods: This was an epidemiological cross-sectional study aimed to find the correlation between age and PSA in the 110 Brazilian Indian tribal men of Macuxi ethnicity. Serum PSA levels (total and free PSA [tPSA and fPSA]) were screened and analyzed considering age groups.

Results: We found that there was a significant correlation between the age and either tPSA ( $p=0.016$ ) or fPSA ( $p=0.036$ ). Interestingly, there was no correlation between tPSA and fPSA with any of the age groups, but we found a significant correlation between PPSA and IPSA in only the age groups $60-69$ years and $70-80$ years $(p=0.008)$.

Conclusion: In this study, we found a significant correlation between tPSA, fPSA, and the age of patients. However, the age-specific correlation was insignificant. From our current findings, we found that the levels of PSA may be considered as an important determinant in determining this correlation and specificity, even though more work needs to be done to verify this. Although PSA screening is a valuable research tool for male patients, the low specificity of the screening might provide false-positive results leading to overtreatment.

Keywords: prostate cancer, prostate-specific antigen, risk stratification, biopsy

\section{Introduction}

Prostate cancer is one of the most common cancers in men, with greater prevalence in developed countries. The worldwide rate of mortality due to prostate cancer in 2008 was estimated to be $28.6 \% .{ }^{1}$ Prostate cancer usually affects older age men, those aged $>50$ years, ${ }^{2}$ with a median age at diagnosis of 72 years. ${ }^{3}$ Prostate-specific antigen (PSA) screening guidelines among different medical organizations vary widely worldwide. In addition, the evidence for PSA screening also remains highly controversial. The literature suggests that no standard of care exists for PSA screening today. There is a marked difference in the incidence of prostate cancer in different geographical areas, which point toward genetic and environmental influences as one of the risk factors. ${ }^{4}$ Ethnicity, diet, aging, and genetic factors are known to play an important role in the prevalence and progression of prostate cancer. ${ }^{5}$ Although there have been demographic and racial differences in incidences of prostate cancer, the epidemiological data on
Correspondence: Mário Maciel de Lima Junior

Department of Urology, State University of Roraima, Rua Levindo Inácio de Oliveira, 1547 Bairro Paraviana, Boa Vista, Roraima, RR. CEP 693|4-550,

Brazi

Tel +5595991230778

$\mathrm{Fax}+559536230174$

Email mmljr@uol.com.br 
prostate cancer in Latin America are scant. ${ }^{6}$ Interestingly, prostate cancer was once identified as the leading cause of cancer death among native American Indian men. ${ }^{7}$ But as of today, data on the incidence and mortality of prostate cancer in Brazilian population or among the indigenous groups in Brazil is insufficient. ${ }^{8}$ This indicates the underreporting of cases of prostate cancer in these areas, due to socioeconomic and geographical difficulties. ${ }^{9}$ Therefore, this study aimed to correlate PSA and age in the tribe of Macuxi ethnicity who hail from the jungles of Amazon (between Brazil and Venezuela).

Screening for prostate cancer is conducted via digital rectal examination and PSA measurement. PSA is an important prognostic factor for prostate cancer development. ${ }^{10,11}$ PSA, an androgen-regulated serine protease, is produced by prostate epithelial cells. ${ }^{12}$ PSA screening has significantly increased the early diagnosis and hence diminished the mortality from prostate cancer. ${ }^{13}$ However, PSA screening is also known to lead to unnecessary biopsies, overdetection, and overtreatment. ${ }^{14}$

Although PSA is organ specific, being produced exclusively by prostate, it is synthesized by both normal and benign prostate tissues, and hence, it is not specific for detecting any malignancy. ${ }^{15}$ In addition, prostate cancer can be present in the absence of elevated PSA. ${ }^{16}$ But the probability of prostate cancer detection increases with increasing total PSA (tPSA) levels. ${ }^{17}$ Most of the PSA in the blood occurs in complexed form, bound to inhibitors, and about $10 \%-30 \%$ of it exists as free PSA (fPSA). ${ }^{14}$ Therefore, in patients with high PSA levels, evaluation of free versus protein-bound PSA is definitive of an underlying prostate abnormality. ${ }^{18}$ fPSA is usually associated with benign conditions, whereas bound PSA is associated with prostate malignancies. Therefore, the ratio of fPSA to tPSA has more clinical relevance in the early detection of prostate abnormality and prevents the further malignancy. ${ }^{19}$ Serum PSA levels and patient age have a direct correlation, which is shown to increase with age, ${ }^{20-22}$ although there are some conflicting reports. ${ }^{23}$ Therefore, reduction in the reference range for PSA levels for younger men will improve the sensitivity resulting in the early detection of prostate cancer. ${ }^{24}$ Moreover, age-specific PSA reference ranges also improve the specificity of the PSA test by raising the PSA threshold for older men. ${ }^{24}$

\section{Patients and methods}

This was an epidemiological, cross-sectional, descriptive, prospective study done on a tribe of Macuxi ethnicity who hailed from the jungles of Amazon (between Brazil and
Venezuela). Indian tribes in the Brazilian Amazon jungle on the border with Venezuela were approached for this study. Men aged $>40$ years were recruited to participate in the study. Laboratory tests were performed and processed by our staff in the city of Boa Vista (300 km from the Indian tribe).

Serum levels of 110 adult males aged $40-80$ years were assessed by the same urologist for fPSA and tPSA. Written informed consent was taken from the patients before they were enrolled for the study. The indigenous people of this region are aware of the Portuguese language, and thus signed/ provided fingerprint on the consent form. The study was approved by the Universidade Federal de Roraima Ethics Committee (number: 21799613.2.0000.5302). The patients were also subgrouped on the basis of age, the 4 age groups being 40-49, 50-59, 60-69, and 70-79 years, to compare the effect of PSA on various age groups. fPSA, tPSA, and the ratio of fPSA to tPSA (relation\%) were used as indicators of risk of prostate cancer in various age groups. Although prostate cancer risk is difficult to assess accurately without prostate biopsy, we inferred it here based on the literature for nonindigenous individuals. ${ }^{25}$

\section{Statistical analysis}

Bivariate correlation analysis was performed using SPSS software to find Pearson's correlation and any significant correlation between the age of all patients and fPSA, age and tPSA, and age and fPSA/tPSA. The same analysis was performed in the 4 subgroups. A $P$-value of $>0.05$ was taken as significant in all the statistical analyses preformed. We also performed a nonparametric analysis, Spearman analysis, to check any correlation. There was no adjustment for multiple analyses. There was no bias in statistical analysis since we did not perform prostatic biopsy in this population. We used the analysis results vis-à-vis literature reports about the risk of prostate cancer in patients with PSA to interpret our results on probable histological risk (based on Gleason gradation).

\section{Results}

For our study, we divided the 110 men included in the study into 4 subgroups according to age: $40-49,50-59,60-69$, and 70-79 years. As shown in Table 1, there is an increasing trend in the median and maximum levels of PSA, with the median value of PSA as low as 0.7 in the age group of 40-49 years and the highest value of 2.0 in the age group of 70-79 years (Table 1). Similarly, the maximum value of PSA showed similar trend, with the lowest value of 2.5 in the age group of 40-49 years and the highest value of 6.5 in the age group 70-79 years (Table 1). Thus, the data point toward a trend of 
Table I Adjustment of PSA for age in I I0 Brazilian Macuxis Indians and estimated prostate cancer risk

\begin{tabular}{llllll}
\hline Age (years) & $\begin{array}{l}\text { Number of } \\
\text { men involved }\end{array}$ & $\begin{array}{l}\text { Medium value } \\
\text { of PSA }\end{array}$ & $\begin{array}{l}\text { Maximum } \\
\text { value of PSA }\end{array}$ & $\begin{array}{l}\text { Prostate } \\
\text { cancer risk (\%) }\end{array}$ & $\begin{array}{l}\text { Prostate cancer risk } \\
\text { Gleason >7 (\%) }\end{array}$ \\
\hline $40-49$ & 31 & 0.7 & 2.5 & 10.1 & 1.0 \\
$50-59$ & 34 & 1.0 & 3.5 & 10.1 & 1.0 \\
$60-69$ & 27 & 1.4 & 4.5 & 17 & 2.0 \\
$70-79$ & 10 & 2.0 & 6.5 & 17 & 2.0 \\
\hline
\end{tabular}

Abbreviation: PSA, prostate-specific antigen.

an increase in the PSA value with an increase in age in the groups. The prostate cancer risk according to the levels of PSA, as can be seen in Table 1, was approximately $10.1 \%$ in the age groups 40-49 and 50-59, whereas the risk increased to $17 \%$ in the age groups $60-69$ and $70-79$ (Table 1). The prostate cancer risk with Gleason score $>7$ was $1 \%$ in the age group 40-49 and 50-59 and $2 \%$ in the age groups $60-69$ and 70-79 (Table 1).

Since the ratio of PPSA and TPSA has been reported to be a better determinant of prostate cancer risk, we aimed to calculate the ratio of fPSA to tPSA in different age groups and compared the median of the groups to conclude if there was any age-related change in PPSA/tPSA in this Indian population. Table 2 shows the median values of fPSA/tPSA after subgrouping the patients by age. We did not find any significant difference in the median values of PPSA/tPSA in all the 4 groups, and there was no change in the prostate cancer probability in most of the age groups.

Since there seems to be an increasing trend in the PSA levels from younger age to older, we next aimed to find out if the trend showed a significant difference and if there was any correlation between the age and PSA values. We therefore performed correlation analysis to find a Pearson coefficient value. We calculated the correlation of individual age groups and their tPSA/fPSA (relation\%), respectively, but did not find any correlation (data not shown). Hence, we next wanted to find out if the tPSA/fPSA (relation\%) of different age groups has any correlation. As shown in Table 3 , there was no significant correlation between the age group and the tPSA values ( $p$-value $>0.05$ in all the 4 groups). The box plot of the data is shown in Figure 1.

Since we could not find any difference in the median values of fPSA/tPSA (relation\%) in any of the 4 groups, we wanted to find out if the cumulative data of the values had any significant correlation with the age group. We did not find any significant correlation between the relation $\%$ and different age groups, except for the age groups 60-69 and 70-79 $(p$-value $=0.008)($ Table 4). Also, a borderline correlation was observed between PSA levels and age groups 40-49
Table 2 Median and maximum values of fPSA/tPSA in different age groups

\begin{tabular}{llll}
\hline Age (years) & $\begin{array}{l}\text { Number of men } \\
\text { involved }\end{array}$ & $\begin{array}{l}\text { fPSA/tPSA } \\
\text { (\%) }\end{array}$ & $\begin{array}{l}\text { Prostate } \\
\text { cancer } \\
\text { probability (\%) }\end{array}$ \\
\hline $40-49$ & 31 & 14.16 & $>28$ \\
$50-59$ & 34 & 13.14 & $>28$ \\
$60-69$ & 27 & 13.73 & $>28$ \\
$70-79$ & 10 & 15.63 & $<28$ \\
\hline
\end{tabular}

Abbreviations: fPSA, free prostate-specific antigen; tPSA, total prostate-specific antigen.

and 70-79 $(p$-value $=0.059)($ Table 4$)$. The box plot of fPSA vs age is shown in Figure 2, and the box plot of relation\% vs age is shown in Figure 3.

Since we believe that subgrouping may reduce the power of the study, we wanted to find out if there was any correlation between age and the PSA levels (tPSA or the ratio) without subgrouping, ie, age was treated as a continuous variable. On performing correlation bivariate analysis on all the patients without subgrouping them, we found a significant correlation of tPSA and age ( $p=0.01)$ (Table 5).

We found a significant correlation between age groups 60-69 and 70-79 years $(p=0.008)$ as shown in Table 4. On performing correlation bivariate analysis on all the patients and the fPSA/tPSA (relation $\%$ ), we could not obtain any significance for this correlation related to age $(p=0.398)$ (Table 6).

We also performed a nonparametric test, Spearman test, to find out if there was any correlation between the age of patients and tPSA (Table 7), fPSA (Table 8), or relation\% (Table 9). We found a significant correlation between the age of patients and tPSA ( $p$-value $=0.023$ ) and fPSA ( $p$-value $=0.014$ ), whereas no correlation was seen with the age of patients and relation $\%(p$-value $=0.485)$.

\section{Discussion}

PSA measurement is an important diagnostic tool to detect the development of prostate cancer, and the likelihood of prostate cancer detection increases with an increase in total PSA levels. ${ }^{10,11,17}$ Our group has recently shown that in the 
Table 3 Pearson correlation between tPSA after subgrouping patients according to age

\begin{tabular}{|c|c|c|c|c|c|}
\hline & $\begin{array}{l}\text { Pearson correlation } \\
\text { parameters }\end{array}$ & tPSAI & tPSA2 & tPSA3 & tPSA4 \\
\hline \multirow[t]{3}{*}{ tPSAI } & Pearson correlation & 1 & 0.038 & 0.104 & -0.363 \\
\hline & Sig (2-tailed) & & 0.851 & 0.583 & 0.273 \\
\hline & $N$ & 30 & 27 & 30 & 11 \\
\hline \multirow[t]{3}{*}{ tPSA2 } & Pearson correlation & 0.038 & 1 & -0.255 & 0.493 \\
\hline & Sig (2-tailed) & 0.851 & & 0.200 & 0.124 \\
\hline & $N$ & 27 & 27 & 27 & 11 \\
\hline \multirow[t]{3}{*}{ tPSA3 } & Pearson correlation & 0.104 & -0.255 & I & -0.082 \\
\hline & Sig (2-tailed) & 0.583 & 0.200 & & 0.811 \\
\hline & $N$ & 30 & 27 & 33 & 11 \\
\hline \multirow[t]{3}{*}{ tPSA4 } & Pearson correlation & -0.363 & 0.493 & -0.082 & I \\
\hline & Sig (2-tailed) & 0.273 & 0.124 & 0.811 & \\
\hline & $\mathrm{N}$ & II & II & II & II \\
\hline
\end{tabular}

Note: Age groups 40-49, 50-59, 60-69, and 70-79 years are depicted as I, 2, 3, and 4, respectively.

Abbreviations: tPSA, total prostate-specific antigen; Sig, significant.

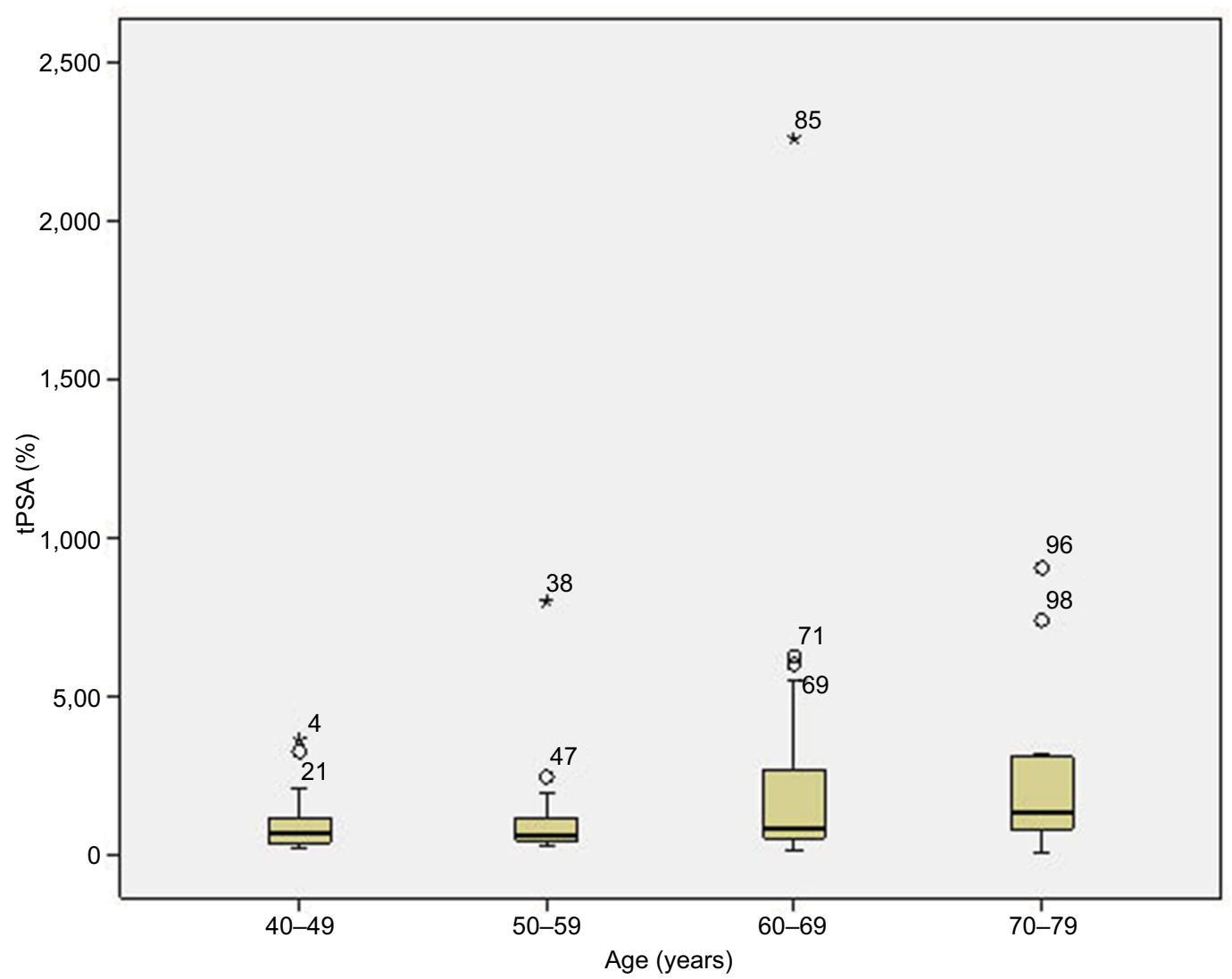

Figure I The box plot of data shows the correlation between the age group and the tPSA values ( $p$-value $<0.05$ in all the 4 groups). Abbreviation: tPSA, total prostate-specific antigen.

Macuxis and Yanomamis tribal population, the testosterone and PSA values were similar with a progressive increase in PSA values with age. ${ }^{26}$ Although there was an increase in the median and maximum PSA values in our study when the patients were subgrouped according to their age groups (Table 1), no significant correlation has been found after performing bivariate analysis to find their correlation with
tPSA (Table 3). This is in agreement with a number of previous studies. ${ }^{20,21,23,27,28}$ There was a significant correlation between the fPSA/tPSA ratio and the age groups 60-69 and 70-79 (Table 4). This significance is promising while comparing patients over 60 years of age, but it is not predictive of early detection of prostate cancer before 60 years of age. Some authors state that the age-specific reference ranges 
Table 4 Pearson correlation between fPSA/tPSA (\%) after subgrouping based on age

\begin{tabular}{|c|c|c|c|c|c|}
\hline & $\begin{array}{l}\text { Pearson correlation } \\
\text { parameters }\end{array}$ & Relation I & Relation 2 & Relation 3 & Relation 4 \\
\hline \multirow[t]{3}{*}{ Relation I } & Pearson correlation & 1 & 0.141 & -0.045 & 0.584 \\
\hline & Sig (2-tailed) & & 0.482 & 0.815 & 0.059 \\
\hline & $N$ & 30 & 27 & 30 & 11 \\
\hline \multirow[t]{3}{*}{ Relation 2} & Pearson correlation & $0.14 \mid$ & I & -0.176 & -0.128 \\
\hline & Sig (2-tailed) & 0.482 & & 0.381 & 0.707 \\
\hline & $\mathrm{N}$ & 27 & 27 & 27 & II \\
\hline \multirow[t]{3}{*}{ Relation 3} & Pearson correlation & -0.045 & -0.176 & I & 0.747 \\
\hline & Sig (2-tailed) & 0.815 & 0.381 & & 0.008 \\
\hline & $N$ & 30 & 27 & 33 & II \\
\hline \multirow[t]{3}{*}{ Relation 4} & Pearson correlation & 0.584 & -0.128 & 0.747 & I \\
\hline & Sig (2-tailed) & 0.059 & 0.707 & 0.008 & \\
\hline & $\mathrm{N}$ & II & II & II & II \\
\hline
\end{tabular}

Notes: Age groups 40-49, 50-59, 60-69, and 70-79 years are depicted as I, 2, 3, and 4, respectively. Bold numbers depict significance.

Abbreviations: fPSA/tPSA, ratio of free prostate-specific antigen to total prostate-specific antigen; Sig, significant.

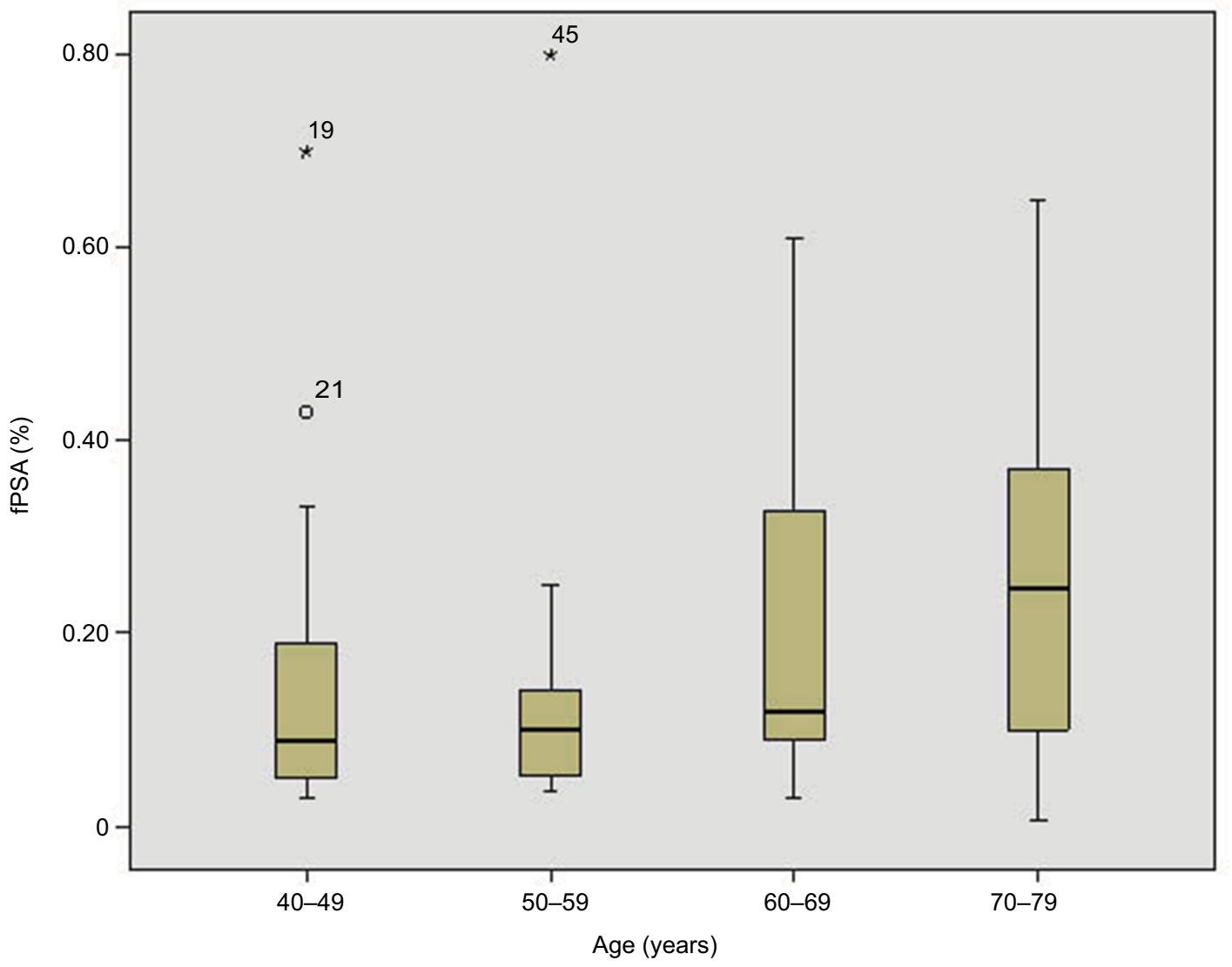

Figure 2 Box plot of fPSA vs age.

Abbreviation: fPSA, free prostate-specific antigen.

have never been officially approved, and no approval of the possible role of PSA screening has been obtained from the manufacturers of the commercially available PSA assays. ${ }^{24}$ We do not rule out the possibility of low number of patients in each group after subdividing them into the 4 age groups, which may provide a false-positive or a false-negative result. To rule out this possibility of low power of the study, we also performed the bivariate analysis on the total patients and compared the age with tPSA, fPSA, and the relation $\%$ (fPSA/tPSA). Interestingly, we did find a significant correlation of patients' age with tPSA (Table 5). But the correlation coefficient value is $<0.3$, so it is considered to have a low positive correlation. To our surprise, there was no correlation between fPSA/tPSA and the age of patients (Table 6). This is 


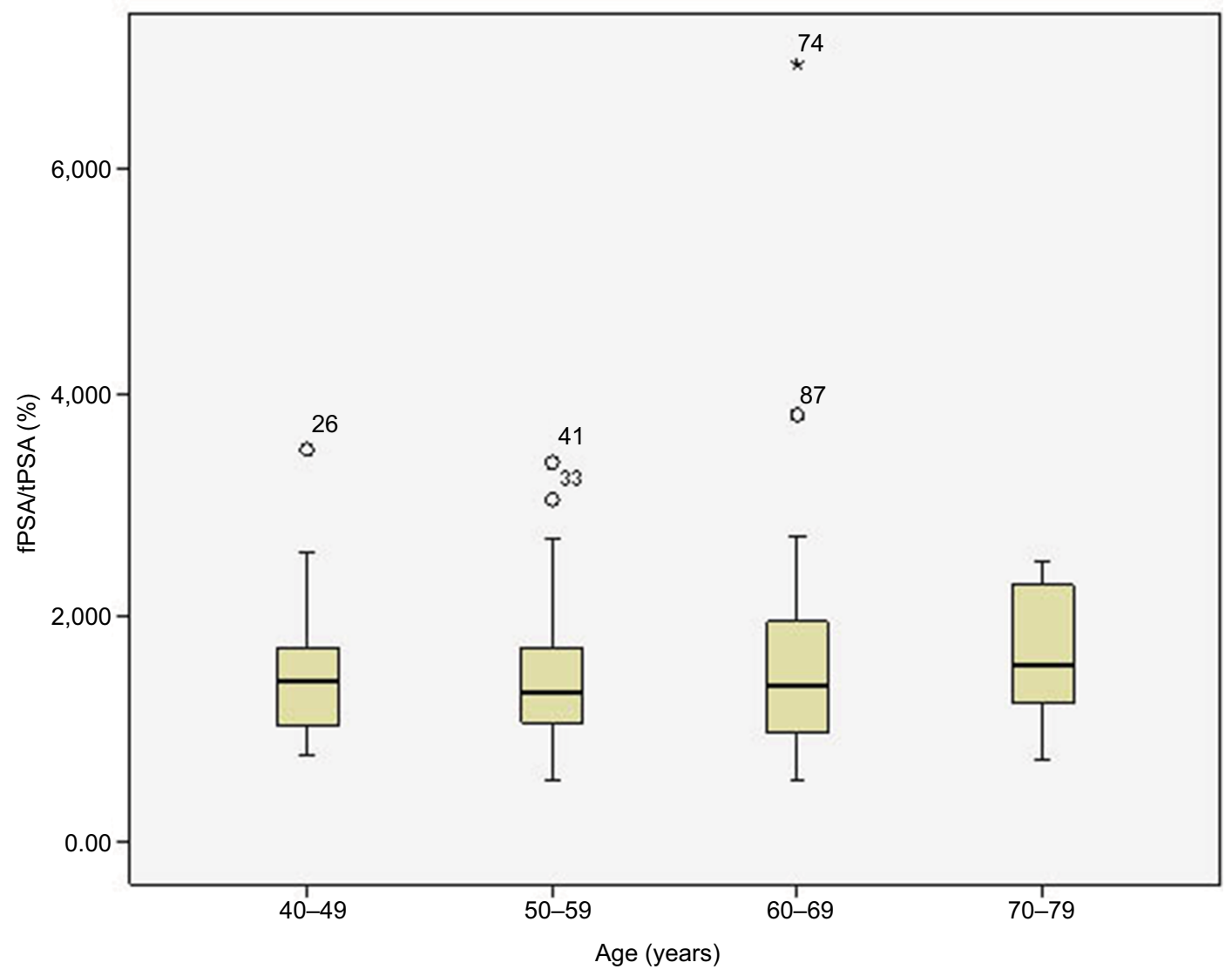

Figure 3 Box plot of fPSA/tPSA vs age.

Abbreviation: fPSA/tPSA, ratio of free prostate-specific antigen to total prostate-specific antigen.

Table 5 Pearson correlation between all ages and tPSA

\begin{tabular}{llll}
\hline & $\begin{array}{l}\text { Pearson orrelation } \\
\text { parameters }\end{array}$ & Age & tPSA \\
\hline Age & Pearson correlation & $\mathrm{I}$ & 0.239 \\
& Sig. (2-tailed) & & $\mathbf{0 . 0 1 6}$ \\
& $\mathrm{N}$ & 101 & 101 \\
tPSA & Pearson correlation & 0.239 & 1 \\
& Sig. (2-tailed) & $\mathbf{0 . 0 1 6}$ & \\
& $\mathrm{N}$ & 101 & 101 \\
\hline
\end{tabular}

Note: Bold numbers depict significance.

Abbreviations: tPSA, total prostate-specific antigen; Sig, significant.

Table 6 Pearson correlation between all ages and fPSA/tPSA

\begin{tabular}{llll}
\hline & $\begin{array}{l}\text { Pearson correlation } \\
\text { parameters }\end{array}$ & Age & tPSA \\
\hline Age & Pearson correlation & $\mathrm{I}$ & 0.085 \\
& Sig. (2-tailed) & & 0.398 \\
& $\mathrm{~N}$ & 101 & 101 \\
tPSA & Pearson correlation & 0.085 & 1 \\
& Sig. (2-tailed) & 0.398 & \\
& $\mathrm{~N}$ & 101 & 101 \\
\hline
\end{tabular}

Abbreviations: fPSA/tPSA, ratio of free prostate-specific antigen to total prostatespecific antigen; Sig, significant.
Table 7 Spearman correlation between all ages and tPSA

\begin{tabular}{lll}
\hline Spearman correlation coefficient & Age & tPSA \\
\hline Age correlation coefficient & $\mathrm{I}$ & 0.226 \\
Sig. (2-tailed) & & $\mathbf{0 . 0 2 3}$ \\
$\mathrm{N}$ & 101 & 101 \\
tPSA correlation coefficient & 0.226 & $\mathrm{I}$ \\
Sig. (2-tailed) & $\mathbf{0 . 0 2 3}$ & \\
$\mathrm{N}$ & 101 & 101 \\
\hline
\end{tabular}

Note: Bold numbers depict significance.

Abbreviations: tPSA, total prostate-specific antigen; Sig, significant.

Table 8 Spearman correlation between all ages and tPSA

\begin{tabular}{lll}
\hline Spearman correlation coefficient & Age & tPSA \\
\hline Age correlation coefficient & $\mathrm{I}$ & 0.249 \\
Sig. (2-tailed) & & $\mathbf{0 . 0 1 4}$ \\
$\mathrm{N}$ & 98 & 98 \\
fPSA correlation coefficient & 0.249 & $\mathrm{I}$ \\
Sig. (2-tailed) & $\mathbf{0 . 0 1 4}$ & \\
$\mathrm{N}$ & 98 & 98 \\
\hline
\end{tabular}

Note: Bold numbers depict significance.

Abbreviations: fPSA, free prostate-specific antigen; Sig, significant. 
Table 9 Spearman correlation between all ages and tPSA \%

\begin{tabular}{lll}
\hline Spearman correlation coefficient & Age & tPSA \\
\hline Age correlation coefficient & $\mathrm{I}$ & 0.070 \\
Sig. (2-tailed) & & 0.485 \\
$\mathrm{~N}$ & 101 & 101 \\
Relation correlation coefficient & 0.070 & $\mathrm{I}$ \\
Sig. (2-tailed) & 0.485 & \\
N & 98 & 98 \\
\hline
\end{tabular}

Abbreviations: tPSA, total prostate-specific antigen; Sig, significant.

again in agreement with previous reports stating that for all the 3 ratios, $\mathrm{f} / \mathrm{tPSA}$ (free to total PSA), c/tPSA (combined to total PSA), and f/cPSA (free to combined PSA), there was no correlation with patient age..$^{22,25}$ Oesterling et $\mathrm{al}^{23}$ stated the possibility that even though there is an increase in the serum concentration of each molecular form with advancing age, this age dependency is lost when the concentration of 1 molecular form is divided by the concentration of another to generate the ratio. ${ }^{22}$ On the other hand, Berger et a ${ }^{29}$ found that PPSA/tPSA significantly increases with age, which according to them may be due to an increase in prostate volume with advancing age.

Several investigators have assessed the impact of race on age-specific PSA reference ranges in prostate cancer and the effect of its ethnogeographical variation in different races. Most of the reports state that PSA levels are higher in black men as compared to white men regardless of age and history of prostate cancer. ${ }^{30,31}$ Some confliction reports do exist, suggesting no significant difference between tPSA levels in African-Americans and white men without prostate cancer in the population of southern Louisiana. ${ }^{32}$ It was suggested that the different genetic and epigenetic factors in this region might be responsible for a different observation in this group of African-Americans and white men. ${ }^{32}$ A study on a Singaporean population also showed no relationship between age and PPA/tPSA ratio. ${ }^{33}$ Similarly, another study on the Korean population failed to find any correlation of PSA with age in prostate cancer. ${ }^{34}$ On the other hand, a study in Chinese men showed a strong correlation of PSA with age. ${ }^{35}$ Our study has the limitations of low power, and among the patients enrolled in our study with prostate cancer indication, only one of them underwent biopsy. This low number is mainly due to the limited availability of medical resources and the limited mobility of the tribal population to hospitals in the city. The same trend was seen in some Asian countries, due to the restricted access to screening programs and urology clinics. ${ }^{4}$ Although the incidence of prostate cancer is high among Asian-American individuals compared to the native
Asian people, the mortality rate is still considerably lower in Western populations than in native Asian populations. This suggests the lack of facilities in these Asian countries, which could help the patients in early detection of the cancer. It also suggests genetic and environmental influences that might account for these variations. ${ }^{4}$ The comparison of some demographic differences in the values of tPSA and \% fPSA/ tPSA in different populations is shown in Table 10. As is clear from the table, there is a similar pattern in the tPSA values in different ethnic groups when compared to the Brazilian Indians in our study (Table 10).

A limitation of our study is that the evaluation of the Brazilian Indian population was limited to PSA measurement and its association with age in a relatively small cohort. Moreover, generally, prostate biopsy is needed for an accurate estimation of prostate cancer risk. However, in this case, we measured the PSA profile of an indigenous population from the Brazilian Amazon region, where people live in remote villages inside the Amazon forest, so it is difficult for them to access health care in urban centers. It is difficult to convince indigenous people to undergo biopsy procedure because of their concern related to cultural issues.

\section{Conclusion}

We found a significant correlation of age with tPSA and fPSA, but this was lost when the patients were subgrouped to find age-specific correlations of PSA levels in the tribal population of Macuxi. Although there are a large number of reports stating the age-dependent role of tPSA, fPSA, and their ratio, the data is still conflicting. It is therefore important to establish appropriate reference ranges for free, complexed, and tPSA as well as the ratios to integrate these new parameters as a diagnostic evaluation tool for early detection of early prostate cancer. ${ }^{19}$ However, high PSA levels do not necessary indicate the presence of prostate cancer, and the cutoff PSA limits needs to be rectified. Decreasing or increasing the cutoff point may help in improving the sensitivity and specificity, since lowering the cutoff point increases the sensitivity, whereas increasing it improves specificity. Although PSA screening is a great beneficial tool for some male patients, the low specificity of the screening might provide false-positive results leading to overtreatment. It is therefore important to focus more on screening patients with an augmented genetic risk of developing prostate cancer, and enhancing the specificity of the PSA screening procedure. More studies need to be done including a large number of patients and using rectified cutoff limits. 
Table 10 Values of tPSA and fPSA/tPSA (\%) in different demographic populations

\begin{tabular}{|c|c|c|c|c|c|c|}
\hline Population & $\begin{array}{l}\text { Age range } \\
\text { (years) }\end{array}$ & tPSA (median) & fPSA/tPSA (\%) & $\begin{array}{l}\text { tPSA }(\mathrm{ng} / \mathrm{mL}) \\
\text { mean } \pm S D\end{array}$ & $\begin{array}{l}\text { fPSA/tPSA } \\
(n g / m L), \\
\text { mean } \pm S D\end{array}$ & Reference \\
\hline Korean & $40-49$ & 0.65 & - & $0.85 \pm 0.69$ & - & 51 \\
\hline Korean & $50-59$ & 0.72 & - & $0.98 \pm 0.86$ & - & 51 \\
\hline Korean & $60-69$ & 0.89 & - & $1.27 \pm 1.23$ & - & 51 \\
\hline Korean & $70-79$ & 1.09 & - & $1.63 \pm 1.60$ & - & 51 \\
\hline Korean & $40-49$ & 0.8 & - & - & - & 56 \\
\hline Korean & $50-59$ & 0.9 & - & - & - & 56 \\
\hline Korean & $60-69$ & 1.0 & - & - & - & 56 \\
\hline Korean & $70-79$ & 1.3 & - & - & - & 56 \\
\hline Chinese & $40-49$ & 0.54 & - & - & - & 50 \\
\hline Chinese & $50-59$ & 0.82 & - & - & - & 50 \\
\hline Chinese & $60-69$ & 0.93 & - & - & - & 50 \\
\hline Chinese & $\geq 70$ & 1.17 & - & - & - & 50 \\
\hline Chinese & $40-49$ & - & - & - & - & 58 \\
\hline Chinese & $50-59$ & 7.3 & - & - & - & 58 \\
\hline Chinese & $60-69$ & 8.4 & - & - & - & 58 \\
\hline Chinese & $70-79$ & 8.5 & - & - & - & 58 \\
\hline Japanese & $40-49$ & 0.6 & - & - & - & 53 \\
\hline Japanese & $50-59$ & 0.7 & - & - & - & 53 \\
\hline Japanese & $60-69$ & 0.9 & - & - & - & 53 \\
\hline Japanese & $70-79$ & 1.4 & - & - & - & 53 \\
\hline Singaporean & $40-49$ & 0.74 & 0.28 & - & - & 48 \\
\hline Singaporean & $50-59$ & 0.86 & 0.29 & - & - & 48 \\
\hline Singaporean & $60-69$ & 1.36 & 0.26 & - & - & 48 \\
\hline Singaporean & $70-79$ & 1.68 & 0.29 & - & - & 48 \\
\hline Other Asian & $40-49$ & - & - & $0.85 \pm 0.57$ & - & 45 \\
\hline Other Asian & $50-59$ & - & - & $1.3 \pm 1.6$ & - & 45 \\
\hline Other Asian & $60-69$ & - & - & $1.8 \pm 1.9$ & - & 45 \\
\hline Other Asian & $70-79$ & - & - & $2.3 \pm 2.3$ & - & 45 \\
\hline Brazilian Indian & $40-50^{\mathrm{a}}$ & 0.66 & 14.16 & $0.91 \pm 0.83$ & $14.9 \pm 6.19$ & Current study \\
\hline Brazilian Indian & $50-60^{a}$ & 0.60 & 13.14 & $1.07 \pm 1.48$ & $15.4 \pm 7.09$ & Current study \\
\hline Brazilian Indian & $60-70^{\mathrm{a}}$ & 0.77 & 13.73 & $2.26 \pm 4.02$ & $16.6 \pm 11.08$ & Current study \\
\hline Brazilian Indian & $70-80^{a}$ & 1.29 & 15.63 & $2.61 \pm 2.95$ & $16.5 \pm 6.5$ & Current study \\
\hline Latino & $40-49^{a}$ & - & - & $0.73 \pm 0.7$ I & & 45 \\
\hline Latino & $49-59^{a}$ & - & - & $1.3 \pm 1.6$ & & 45 \\
\hline Latino & $59-69^{a}$ & - & - & $1.8 \pm 2.1$ & & 45 \\
\hline Latino & $69-79^{a}$ & - & - & $2.0 \pm 2.3$ & & 45 \\
\hline African-American & $40-49$ & - & - & $2.14 \pm 1.16$ & & 52 \\
\hline African-American & $50-59$ & - & - & $4.56 \pm 0.94$ & & 52 \\
\hline African-American & $60-69$ & - & - & $6.70 \pm 0.99$ & & 52 \\
\hline African-American & $70-79$ & - & - & $|1.22 \pm 2.3|$ & & 52 \\
\hline African-American & $40-49$ & 0.7 & - & - & - & 55 \\
\hline African-American & $50-59$ & 0.9 & - & - & - & 55 \\
\hline African-American & $60-69$ & 1.1 & - & - & - & 55 \\
\hline African-American & $70-79$ & - & - & - & - & 55 \\
\hline African-American & $40-49$ & 0.72 & - & $0.87 \pm 0.58$ & - & 47 \\
\hline African-American & $50-59$ & 0.92 & - & $1.21 \pm 1.07$ & - & 47 \\
\hline African-American & $40-49$ & 0.74 & 24.1 & - & - & 61 \\
\hline African-American & $50-59$ & 0.78 & 26.9 & - & - & 61 \\
\hline African-American & $60-69$ & 1.21 & 25.6 & - & - & 61 \\
\hline African-American & $70-79$ & 1.21 & 24.1 & - & - & 61 \\
\hline Black African-American & $40-49$ & - & - & $0.87 \pm 0.92$ & - & 45 \\
\hline Black African-American & $50-59$ & - & - & $1.4 \pm 1.6$ & - & 45 \\
\hline Black African-American & $60-69$ & - & - & $2.0 \pm 2.4$ & - & 45 \\
\hline Black African-American & $70-79$ & - & - & $2.5 \pm 2.7$ & - & 45 \\
\hline
\end{tabular}


Table 10 (Continued)

\begin{tabular}{|c|c|c|c|c|c|c|}
\hline Population & $\begin{array}{l}\text { Age range } \\
\text { (years) }\end{array}$ & tPSA (median) & fPSA/tPSA (\%) & $\begin{array}{l}\text { tPSA }(\mathrm{ng} / \mathrm{mL}) \text {, } \\
\text { mean } \pm \mathrm{SD}\end{array}$ & $\begin{array}{l}\text { fPSA/tPSA } \\
(\mathrm{ng} / \mathrm{mL}) \\
\text { mean } \pm \text { SD }\end{array}$ & Reference \\
\hline 9 European and 8 non-European & $40-49$ & 0.64 & 34.5 & - & - & 59 \\
\hline 9 European and 8 non-European & $50-59$ & 0.76 & 31.5 & - & - & 59 \\
\hline 9 European and 8 non-European & $60-69$ & 0.94 & 31.8 & - & - & 59 \\
\hline 9 European and 8 non-European & $69-79$ & 1.03 & 33.6 & - & - & 59 \\
\hline Turkish & $40-49$ & - & - & - & - & 60 \\
\hline Turkish & $50-59$ & 5.5 & - & $11.7 \pm 19.7$ & - & 60 \\
\hline Turkish & $60-69$ & 11.9 & - & $16.3 \pm 14.9$ & - & 60 \\
\hline Turkish & $69-79$ & 12.4 & - & $19.1 \pm 16.5$ & - & 60 \\
\hline White American & $40-49$ & - & - & $3.25 \pm \mathrm{I} .42$ & - & 52 \\
\hline White American & $50-59$ & - & - & $3.40 \pm 0.50$ & - & 52 \\
\hline White American & $60-69$ & - & - & $4.68 \pm 0.39$ & - & 52 \\
\hline White American & $70-79$ & & & $4.29 \pm 0.36$ & - & 52 \\
\hline White American & $40-49$ & 0.6 & - & - & - & 54 \\
\hline White American & $50-59$ & 0.75 & - & - & - & 54 \\
\hline White American & $60-69$ & 1.0 & - & - & - & 54 \\
\hline White American & $70-79$ & 1.6 & - & - & - & 54 \\
\hline White American & $40-49$ & - & - & $0.82 \pm 0.77$ & - & 45 \\
\hline White American & $50-59$ & - & - & $1.2 \pm 1.3$ & - & 45 \\
\hline White American & $60-69$ & - & - & $1.8 \pm 1.9$ & - & 45 \\
\hline White American & $70-79$ & - & - & $2.3 \pm 2.3$ & - & 45 \\
\hline White American & $40-49$ & - & - & - & - & 55 \\
\hline White American & $50-59$ & 0.8 & - & - & - & 55 \\
\hline White American & $60-69$ & 1.0 & - & - & - & 55 \\
\hline White American & $70-79$ & - & - & - & - & 55 \\
\hline White American & $40-49$ & - & - & - & - & 43 \\
\hline White American & $50-59$ & 0.94 & 25.8 & - & - & 43 \\
\hline White American & $60-69$ & 1.33 & 24.9 & - & - & 43 \\
\hline White American & $70-79$ & 1.75 & 25.1 & - & - & 43 \\
\hline White American & $40-49$ & 0.70 & - & $0.8 I \pm 0.54$ & - & 47 \\
\hline White American & $50-59$ & 0.97 & - & $1.35 \pm 1.54$ & - & 47 \\
\hline White American & $60-69$ & 1.17 & - & $1.8 \mathrm{I} \pm 2.65$ & - & 47 \\
\hline White American & $70-79$ & - & - & - & - & 47 \\
\hline American & $40-49$ & 0.65 & 0.31 & - & - & 33 \\
\hline American & $50-59$ & 0.85 & 0.3 & - & - & 33 \\
\hline American & $60-69^{a}$ & 1.39 & 0.27 & - & - & 33 \\
\hline American & $69-79^{a}$ & 1.64 & 0.28 & - & - & 33 \\
\hline American & $40-49$ & - & - & - & - & 40 \\
\hline American & $50-59$ & - & - & $1.32 \pm 1.10$ & - & 40 \\
\hline American & $60-69^{a}$ & - & - & $1.91 \pm 1.72$ & - & 40 \\
\hline American & $69-79^{a}$ & - & - & $2.36 \pm 1.98$ & - & 40 \\
\hline American & $45-59$ & - & - & $6.3 \pm 2.8$ & - & 57 \\
\hline American & $60-69$ & - & - & $7.1 \pm 3.1$ & - & 57 \\
\hline American & $70-79$ & - & - & $7.6 \pm 3.3$ & - & 57 \\
\hline American & $>80$ & - & - & $8.8 \pm 3.9$ & - & 57 \\
\hline
\end{tabular}

Notes: ${ }^{\text {TT }}$ The authors confirm it is correct that some age values $(49,59,69$ and $50,60,70)$ appear in two different groups, and advise this is because the study is a comparison of demographic differences in the values of tPSA and \% fPSA/tPSA in different populations. We found there is a similar pattern in the tPSA values in different ethnic groups when compared to the Brazilian Indians in our study. For this reason we have placed the same age values in two groups.

Abbreviations: fPSA/tPSA, ratio of free prostate-specific antigen to total prostate-specific antigen; tPSA, total prostate-specific antigen.

\section{Author contributions}

MMLJr participated in the preparation of the manuscript, collected the data, and carried out the sample collection and examination. SSJF collected the data and carried out the sample processing and analysis. MTM participated in the preparation of the manuscript and analyzed the statistics. All authors contributed toward data analysis, drafting and critically revising the paper, gave final approval of the version to be published, and agree to be accountable for all aspects of the work.

\section{Disclosure}

The authors report no conflicts of interest in this work. 


\section{References}

1. Ferlay J, Parkin DM, Steliarova-Foucher E. Estimates of cancer incidence and mortality in Europe in 2008. Eur J Cancer. 2010;46(4):765-781.

2. Bono AV. The global state of prostate cancer: epidemiology and screening in the second millennium. BJU Int. 2004;94(Suppl 3):1-2.

3. National Cancer Institute. Prostate Cancer Treatment (PDQ $\left.{ }^{\circledR}\right)$ - Health Professional Version. General Information About Prostate Cancer; 2015 [updated March 31, 2017; cited September 2, 2015]. Available from: http://www.cancer.gov/cancertopics/pdq/treatment/prostate/HealthProfessional/. Accessed June 1, 2018.

4. Ito K. Prostate cancer in Asian men. Nat Rev Urol. 2014;11(4):197-212.

5. Cussenot $\mathrm{O}$, Valeri A. Heterogeneity in genetic susceptibility to prostate cancer. Eur J Int Med. 2001;12(1):1-16.

6. Faria EF, Carvalhal GF, Vieira RA, Silva TB, Mauad EC, Carvalho AL. Program for prostate cancer screening using a mobile unit: results from Brazil. Urology. 2010;76(5):1052-1057.

7. Gilliland FD, Key CR. Prostate cancer in American Indians, New Mexico, 1969-1994. J Urol. 1998;159:893-898.

8. Facina T. Estimativa 2012 - Incidencia de Cancer no Brasil. Revista Brasileira de Cancerologia. 2011;57:557.

9. De Lima MM Jr, de Lima MM, Granja F. Prostate cancer in Amazon native Indian: a case report. Asian Pharm Tech. 2014;2:1-5.

10. Candas B, Labrie F, Gomez JL, et al. Relationship among initial serum prostate specific antigen, prostate specific antigen progression and prostate cancer detection at repeat screening visits. $J$ Urol. 2006;175(2):510-516.

11. McGreevy K, Rodgers K, Lipsitz S, Bissada N, Hoel D. Impact of race and baseline PSA on longitudinal PSA. Int J Cancer. 2006;118(7):1773-1776.

12. Balk SP, Ko YJ, Bubley GJ. Biology of prostate-specific antigen. J Clin Oncol. 2003;21(2):383-391.

13. Miller BA, Chu KC, Hankey BF, Ries LA. Cancer incidence and mortality patterns among specific Asian and Pacific Islander populations in the U.S. Cancer Causes Control. 2008;19(3):227-256.

14. Duffy MJ. PSA in screening for prostate cancer: more good than harm or more harm than good? Adv Clin Chem. 2014;66:1-23.

15. Stenman UH, Hakama M, Knekt P, Aromaa A, Teppo L, Leinonen J. Serum concentrations of prostate specific antigen and its complex with $\alpha_{1}$-antichymotrypsin before diagnosis of prostate cancer. Lancet. 1994;344(8937):1594-1598.

16. Thompson I, Pauler D, Goodman P, et al. Prevalence of prostate cancer among men with a prostate-specific antigen level $\leq 4.0 \mathrm{ng}$ per milliliter. N Engl J Med. 2004;350(22):2239-2246.

17. Catalona WJ, Richie JP, Ahmann FR, et al. Comparison of digital rectal examination and serum prostate specific antigen in the early detection of prostate cancer: results of a multicentre clinical trial of 6,630 men. J Urol. 1994;151(5):1283-1290.

18. Lee R, Localio AR, Armstrong K, et al. A meta-analysis of the performance characteristics of the free prostate-specific antigen test. Urology. 2006;67(4):762-768.

19. Miele ME. Percent free PSA as an additional measure in a prostate cancer screen. Clin Lab Sci. 2001;14(2):102-107.
20. Collins GN, Lee RJ, McKelvie GB, Rogers AC, Hehir M. Relationship between prostate specific antigen, prostate volume and age in the benign prostate. Brit J Urol. 1993;71(4):445-450.

21. Oesterling JE, Jacobsen SJ, Chute CG, et al. Serum prostate specific antigen in a community based population of healthy men: establishment of age-specific reference ranges. JAMA. 1993;270(7):860-864.

22. Luderer AA, Chen YT, Soriano TF, et al. Measurement of the proportion of free to total prostate specific antigen improves diagnostic performance of prostate specific antigen in the diagnostic grey zone of total prostate specific antigen. Urology. 1995;46(2):187-194.

23. Oesterling JE, Jacobsen SJ, Klee GG, et al. Free, complexed and total prostate specific antigen: the establishment of appropriate reference ranges for their concentrations and ratios. $J$ Urol. 1995;154(3): 1090-1095.

24. Luboldt HJ, Schindler FS, Rubben H. Age-specific reference ranges for prostate-specific antigen as a marker for prostate cancer. Eur Urol. 2007;5:38-48

25. Kalish LA, McKinlay JB. Serum prostate-specific antigen levels (PSA) in men without clinical evidence of prostate cancer: age-specific reference ranges for total PSA, free PSA, and percent free PSA. Urology. 1999;54(6):1022-1027.

26. De Lima Junior MM, Reis LO, Ferreira U, et al. Unraveling Brazilian Indian Population prostate good health: clinical, anthropometric and genetic features. Int Braz J Urol. 2015;41(2):344-352.

27. Dalkin BL, Ahmann FR, Kopp JB. Prostate specific antigen levels in men older than 50 years without clinical evidence of prostatic carcinoma. J Urol. 1993;150(6):1837-1839.

28. Crawford ED. Report on the 1993 prostate cancer awareness week. Abstract presented at: Annual Meeting of the American Urological Association; May 14-19, 1994; San Francisco, CA, USA.

29. Berger AP, Cheli C, Levine R, Klocker H, Bartsch G, Horninger W. Impact of age on complexed PSA levels in men with total PSA levels of up to $20 \mathrm{ng} / \mathrm{mL}$. Urology. 2003;62(5):840-844.

30. DeAntoni EP, Crawford ED, Oesterling JE, et al. Age and race-specific reference ranges for prostate-specific antigen from a large communitybased study. Urology.1996;48(2):234-239.

31. Moul JW, Sesterhenn IA, Conelly RR, et al. Prostate specific antigen values at the time of prostate cancer diagnosis in African-American men. JAMA. 1995;274(16):1277-1281.

32. Martin B, Cheli C, Pollard S, et al. Similar age-specific PSA, complexed PSA, and percent cPSA levels among African-American and white men of southern Louisiana. Prostate-specific antigen. Urology. 2003;61(2):375-379.

33. Saw S, Aw TC. Age-related reference intervals for free and total prostate-specific antigen in a Singaporean population. Pathology. 2000;32(4):245-249.

34. Kim JH, Lee SW, Kim JH, et al. Association between obesity, prostatespecific antigen level and prostate-specific antigen density in men with a negative prostate biopsy. J Int Med Res. 2014;42(3):821-827.

35. He D, Wang M, Chen X, et al. Ethnic differences in distribution of serum prostate-specific antigen: a study in a healthy Chinese male population. Urology. 2004;63(4):722-726.
Research and Reports in Urology

\section{Publish your work in this journal}

Research and Reports in Urology is an international, peer-reviewed, open access journal publishing original research, reports, editorials, reviews and commentaries on all aspects of adult and pediatric urology in the clinic and laboratory including the following topics: Pathology, pathophysiology of urological disease; Investigation and treatment of

\section{Dovepress}

urological disease; Pharmacology of drugs used for the treatment of urological disease. The manuscript management system is completely online and includes a very quick and fair peer-review system, which is all easy to use. Visit http://www.dovepress.com/testimonials.php to read real quotes from published authors. 